OPEN ACCESS

Edited by:

Jens Staal,

Ghent University, Belgium

Reviewed by:

Zonghua Wang,

Fujian Agriculture and Forestry

University, China

Lizelle Ann Piater,

University of Johannesburg,

South Africa

*Correspondence:

Chang-Jie Jiang

cjijiang@affrc.go.jp

Zheng-Wei Liang

liangzw@neigae.ac.cn

Specialty section:

This article was submitted to

Plant Microbe Interactions,

a section of the journal

Frontiers in Plant Science

Received: 05 July 2017

Accepted: 25 August 2017 Published: 06 September 2017

Citation:

Jiang C-J, LiU X-L, LiU X-Q, Zhang $H, Y u Y-J$ and Liang $Z-W$ (2017) Stunted Growth Caused by Blast Disease in Rice Seedlings is Associated with Changes in Phytohormone Signaling Pathways.

Front. Plant Sci. 8:1558.

doi: 10.3389/fpls.2017.01558

\section{Stunted Growth Caused by Blast Disease in Rice Seedlings Is Associated with Changes in Phytohormone Signaling Pathways}

\author{
Chang-Jie Jiang ${ }^{1 *}$, Xiao-Long Liu², Xin-Qiong Liu ${ }^{3}$, Hui Zhang ${ }^{2}$, Ying-Jie Yu² and \\ Zheng-Wei Liang ${ }^{2 *}$
}

\begin{abstract}
${ }^{1}$ Institute of Agrobiological Sciences, National Agriculture and Food Research Organization, Tsukuba, Japan, ${ }^{2}$ Northeast Institute of Geography and Agroecology, Chinese Academy of Sciences, Changchun, China, ${ }^{3}$ College of Life Science,

South-Central University for Nationalities, Wuhan, China
\end{abstract}

In response to pathogen attack, plants prioritize defense reactions generally at the expense of plant growth. In this work, we report that changes in phytohormone signaling pathways are associated with the stunted plant growth caused by blast disease in rice seedlings. Infection of rice seedlings with blast fungus Magnaporthe oryzae (race 007.0) at the four-leaf stage (three true leaves) resulted in considerable inhibition of the growth of the upper uninfected distal leaves; the length of leaf blade and leaf sheath of the sixth and seventh leaf was reduced by 27 and $82 \%$, and 88 and $72 \%$, respectively, compared to that in the uninoculated plant control. Interestingly, cutting off the blast-infected fourth leaf blade within 2 days post inoculation (dpi) significantly rescued the inhibition of leaf growth, implying that an inhibitory substance(s) and/or signal was generated in the blast-infected leaves (fourth leaf) and transmitted to the upper distal leaves (sixth and seventh) during the 2-dpi period that induced growth inhibition. Expression analysis of marker genes for phytohormone pathways revealed acute activation of the jasmonate (JA) and abscisic acid (ABA) signaling pathways, and repression of auxin, gibberellic acid (GA) and salicylic acid (SA) signaling pathways, in the sixth leaf. The genes related to cell wall expansion were also significantly downregulated. In the blast-infected fourth leaf, JA pathway was activated within $2 \mathrm{dpi}$, followed by activation of ABA pathway $3 \mathrm{dpi}$. Further, leaf inhibition caused by blast infection was partially rescued in the rice mutant line coleoptile photomorphogenesis 2 (cpm2), which is defective in the gene encoding allene oxide cyclase (OsAOC). These results indicate that the JA signaling pathway is at least partly involved in the growth inhibition processes. Collectively, our data suggest that, upon pathogen attack, rice seedlings prioritize defense reactions against the infecting pathogen by temporarily ceasing plant growth through the systemic control of phytohormone pathways.

Keywords: phytohormones, growth, defense, trade-off, Magnaporthe oryzae, rice 


\section{INTRODUCTION}

Plants have evolved a set of mechanisms to tune the balance of plant growth and defense reactions for better survival and fitness in nature. In response to pathogen attack, plants allocate more resources toward defense reactions, while temporarily limiting the supply of nutrients and energy resources to less urgent physiological processes such as photosynthesis and plant growth (Huot et al., 2014; Takatsuji, 2017). Consequently, defense responses negatively impact plant fitness because of their usage of highly costly resources. Therefore, plants generally restore the balance to favor growth and development in the absence of pathogen challenges (Huot et al., 2014; Takatsuji, 2017). In addition, rather than deploying defense mechanisms uniformly across different tissues, plants prioritize protecting the tissues that contribute more to a plant's future fitness, such as young sink tissues and reproductive structures (optimal defense hypothesis, ODH) (Meldau et al., 2012; Meldau and Baldwin, 2013). While the molecular mechanisms remain largely unknown, recent studies have implicated that a complex signaling network involving phytohormones plays a major role in such a trade-off between growth and defense (Huot et al., 2014; Kazan and Lyons, 2014; Takatsuji, 2017). Phytohormones play central signaling roles in diverse biological processes including plant growth and development, as well as defense responses. Each of the hormones generates and transmits a distinct growth and/or defense signal, while crosstalk between them has been shown to be essential for the outcome of plant-pathogen interactions (Robert-Seilaniantz et al., 2011; Yang et al., 2013; Huot et al., 2014; Takatsuji and Jiang, 2014). It has been well documented that salicylic acid (SA), jasmonates (JA), and ethylene (ET) play key roles in activation of defense responses to various pathogens (Robert-Seilaniantz et al., 2011; Yang et al., 2013; Huot et al., 2014; Takatsuji and Jiang, 2014). It was shown that a heat shock factor-like transcription factor, TBF1, plays a key role in the growth-to-defense transition in response to SA and the MAMP signal, elf18, in Arabidopsis (Pajerowska-Mukhtar et al., 2012). Other growth-regulating hormones, such as auxin, gibberellic acid (GA), cytokinins (CKs), and abscisic acid (ABA), also have an important part to play in plant-pathogen interactions via cooperative or antagonistic crosstalk with the defense hormones, SA, JA, and ET (Robert-Seilaniantz et al., 2011; Yang et al., 2013; Takatsuji and Jiang, 2014; Ma and Ma, 2016).

In rice, SA has been implicated in activation of defense responses to various pathogens including blast fungus Magnaporthe oryzae and leaf-blight bacteria Xanthomonas oryzae pv. oryzae (Schweizer et al., 1999; Rohilla et al., 2002; Babu et al., 2003; Yang et al., 2004; Shimono et al., 2007; Sugano et al., 2010). The SA signaling in rice is mediated by two downstream factors, OsNPR1 and WRKY45 (Shimono et al., 2007; Sugano et al., 2010), unlike that in Arabidopsis where it is primarily mediated by NPR1 (Wang et al., 2006). JA and ET are also involved in resistance to rice pathogens $M$. oryzae, $X$. oryzae pv. oryzae, and Rhizoctonia solani (Iwai et al., 2006; Mei et al., 2006; Bailey et al., 2009; Seo et al., 2011; Yamada et al., 2012; Helliwell et al., 2013; Riemann et al., 2013). In contrast to the mostly antagonistic interaction between SA- and JA-mediated signaling pathways in Arabidopsis, it was shown that SA and JA activate a common defense system in rice (Brooks et al., 2005; Laurie-Berry et al., 2006; Robert-Seilaniantz et al., 2011; Garg et al., 2012; Tamaoki et al., 2013). The growth hormones auxin and GAs have been shown to negatively affect rice resistance to $M$. oryzae, X. oryzae pv. Oryzae, and Xanthomonas oryzae pv. oryzicola (Tanaka et al., 2006; Ding et al., 2008; Yang et al., 2008; Domingo et al., 2009; Fu et al., 2011). Auxin was shown to upregulate expansin gene expression, leading to cell wall loosening, and thus rendering the plant more susceptible to pathogen invasions (Ding et al., 2008; Domingo et al., 2009). It was further shown that overexpression of OsNPR1 in rice plants resulted in growth attenuation (dwarf phenotype) by repressing auxin signaling pathway through upregulating $\mathrm{OsGH3} .8$, a gene encoding IAA-amino synthase (Li et al., 2016). Yang et al. (2012) reported that JA antagonistically interacts with GA signaling cascade to prioritize defense over growth upon pathogen attacks in both Arabidopsis and rice. We previously showed that CKs and $\mathrm{ABA}$ interact with SA cooperatively and antagonistically, respectively, in rice- $M$. oryzae interaction (Jiang et al., 2010, 2013).

It has been shown that rice plants diseased by virus and blast fungus exhibit growth stunting. Rice infection by rice stripe virus (RSV) (Satoh et al., 2010), rice dwarf virus (RDV) (Satoh et al., 2011), rice grassy stunt virus (RGSV) (Satoh et al., 2013) and rice tungro spherical virus (RTSV) (Budot et al., 2014) result in a severe growth stunting. Molecular analysis revealed that the virus infection-induced growth inhibition is associated with suppression of GA and/or auxin signaling cascades and cell wall synthesis and expansion (Satoh et al., 2010, 2011, 2013; Budot et al., 2014). On the other hand, several decades ago, it was observed that infection of rice seedlings with blast fungus $M$. oryzae results in a severe growth inhibition in addition to formation of blast disease lesions at the infection sites; this morphological symptom is called "Zurikomi" that means stunting of plant growth in Japanese (Tokunaga et al., 1959). The growth inhibition is manifested the most in successive upper two to three leaves counted from the infected leaf, especially in the early stages of plant growth (Tokunaga et al., 1959; Yoshida et al., 1992). Microscopic observation suggested that the suppression of cell division is a major factor for stunting of blastinfected plants (Yoshida et al., 1992). It was initially thought that the growth stunting is caused by excess accumulation of coumarin within plants triggered by the blast fungal toxin piricularin (Tamari and Kaji, 1959a,b). This, however, could not be confirmed in later studies (Satoh and Kozaka, 1966, 1971). Moreover, ethylene evolution was detected from blast inoculated rice plants (Kozaka and Teraoka, 1977), but which was found not be associated with growth stunting of blast-infected rice plants (Yoshioka et al., 1992). Thus, the detailed mechanism of the growth stunting in blast-infected rice plants remains largely unknown.

In this study, we report that a yet unknown inhibitory substance(s) and/or signal(s) is generated in the M. oryzaeinfected leaves and transmitted to the upper distal leaves, where it activates JA and ABA, while suppressing GA and auxin signaling pathways, and consequently causing an inhibition of growth 
in the leaves. These findings provide new insights into the controlling mechanism of growth-defense balance in plants.

\section{MATERIALS AND METHODS}

\section{Plant Materials and Measurements}

The Japonica rice cultivar 'Nipponbare' was used in this study. Seeds were germinated in soil (Bonsol No. 2; Sumitomo Chemical Corp., Tokyo, Japan) in plastic pots (50 $\mathrm{mm}$ square $\times 50 \mathrm{~mm}$ deep, and a drainage hole), four seeds per pot, and the seedlings were grown in a greenhouse at $28^{\circ} \mathrm{C}$ in the day $(14 \mathrm{~h})$ and $23^{\circ} \mathrm{C}$ in the night $(10 \mathrm{~h})$. The relative humidity in the greenhouse was approximately $70 \%$.

A rice mutant line coleoptile photomorphogenesis 2 $($ cpm2) defective in the gene encoding allene oxide cyclase (OsAOC) (Biswas et al., 2003) and its wild-type (WT) rice line 'Nihonmasari' were used for investigation of the role of JA in growth stunting of blast-infected rice plants. The homozygous mutant seedlings were selected from a heterozygous population based on phenotype of elongated shoots compared with WT. The homozygosity of mutant seedlings was further confirmed by PCR genotyping, using primer set, $5^{\prime}$-ACGAACATCTCCTGCACCTT-3' and 5'-CTCGCGAGTCTCCGTCAG-3'.

About 4-5 weeks after blast inoculation, the fully grown fifth to seventh leaves were detached from shoot bases, and measured for lengths of leaf blades and leaf sheaths with a scaled ruler.

\section{Pathogen Culture and Inoculations}

Culture and inoculations of the blast fungus $M$. oryzae (race 007.0) were carried out according to Akagi et al. (2015). Briefly, the fungus was grown on an oatmeal agar medium $(30 \mathrm{~g} / \mathrm{L}$ oatmeal, $5 \mathrm{~g} / \mathrm{L}$ sucrose, and $16 \mathrm{~g} / \mathrm{L}$ agar) at $26^{\circ} \mathrm{C}$ for $10-12$ days. Conidia formation was induced by irradiation under continuous black-blue light (FL15BLB; Toshiba, Osaka, Japan) at $24^{\circ} \mathrm{C}$ for 2-4 days. The conidia were suspended in $0.02 \%$ Silwet L-77 at a density of $1-2 \times 10^{5} / \mathrm{mL}$ and sprayed onto rice plants at the fourleaf stage. As a mock treatment control, the same volume of $0.02 \%$ Silwet L-77 was sprayed. After incubation in a dew chamber at $24^{\circ} \mathrm{C}$ for $24 \mathrm{~h}$, the rice plants were moved back to the greenhouse.

\section{Gene Expression Analysis}

Rice seedlings at the four-leaf stage were blast-inoculated, and the inoculated fourth leaf blades of half the plants was cut off at $2 \mathrm{dpi}$. Sixth whole leaf was collected at $3 \mathrm{dpi}$, and leaf blades and leaf sheathes separately at $6 \mathrm{dpi}$. Three biological replicates were collected, four leaves in each replicate.

Real time-polymerase chain reaction (RT-PCR) was used to analyze the samples for expression of marker genes for JA (JAmyb and OMT), ABA (SalT and OsWsi18), auxin (ARF1 and IAA9), GA (OsGA2ox3 and OsGA20ox1) and SA (WRKY45 and OsNPR1), and PR genes OsPR1b and PBZ1. The genes and primer sequences used for qRT-PCR are listed in Supplementary Table 1.

Total RNA was isolated using the TRIzol reagent (Invitrogen) and reverse-transcribed by using ReverTra Ace (TOYOBO,
Osaka, Japan) according to the manufacturer's protocol. Quantitative RT-PCR (qRT-PCR) was run on a Thermal Cycler Dice TP800 system (Takara Bio) using SYBR premix ExTaq mixture (Takara Bio) as previously described (Shimono et al., 2007).

\section{Phytohormone Treatments and Measurements}

All stock solutions, except brassinolide (BR), were prepared at a concentration of $100 \mathrm{mM}$ as described previously (Jiang et al., 2009). BR was prepared at $20 \mathrm{mM}$ concentration. Indole3-acetic acid (IAA; Sigma, St. Louis, MO, United States), gibberellin A3 (GA3; Wako, Osaka, Japan), ABA [( \pm )-cis-trans, Sigma], methyl jasmonate (ME-JA; Wako), and brassinolide (BR; Wako) were dissolved in absolute ethanol. Kinetin (Sigma) and benzothiadiazole $S$-methyl ester (BTH; Wako) were dissolved in dimethyl sulfoxide (DMSO); and 1-aminocyclopropane-1carboxylic acid (ACC; Sigma) and sodium salicylate (SA; Nacalai Tesque, Tokyo, Japan) in $\mathrm{H}_{2} \mathrm{O}$.

For plant treatments, rice seedlings at four-leaf stage (three true leaves) were transferred to a container containing each of the phytohormone solutions at $50 \mu \mathrm{M}$ for IAA, GA3, CK, ACC, $\mathrm{ABA}, \mathrm{JA}$, and BTH, and at $10 \mu \mathrm{M}$ for BR. Water was used as mock control. The rice seedlings were further grown for 4 weeks, and leaf lengths of the fifth leaf were measured.

Measurement of JA and ABA content were performed as described previously (Kojima and Sakakibara, 2012).

\section{Experimental Design and Data Analysis}

All the experiments were conducted with three replicates each consisting of one to two planting pots with four plants per pot for each inoculation. The plants for each replicate were placed in a separate container, and the three replicate containers were rotated within the growth chamber every $2-3$ days to minimize any effect of location. All the experiments were repeated at least twice independently; these produced similar results, so data from only one trial are presented.

Statistical analyses were performed using the statistical software SPSS 21.0 (IBM Corp., Armonk, NY, United States). One-way analysis of variance (ANOVA) was used to compare differences in the means among treatments $(P=0.05)$.

Calculations of mean values and standard deviations, graph plotting and correlation analysis were performed using Microsoft Office 365-Excel software (Microsoft Corporation, Tokyo, Japan).

\section{RESULTS}

\section{Blast Infection Caused Growth Inhibition of Rice Seedlings}

Rice seedlings at four-leaf stage, with fourth leaves fully expanded, were inoculated with a compatible blast fungus race 007 . Visible blast disease lesions appeared on the fourth leaf blades at $3 \mathrm{dpi}$ and the fourth leaf blades were wilted by $7 \mathrm{dpi}$ (data not shown). From then on, upper leaves above the inoculated fourth leaves 

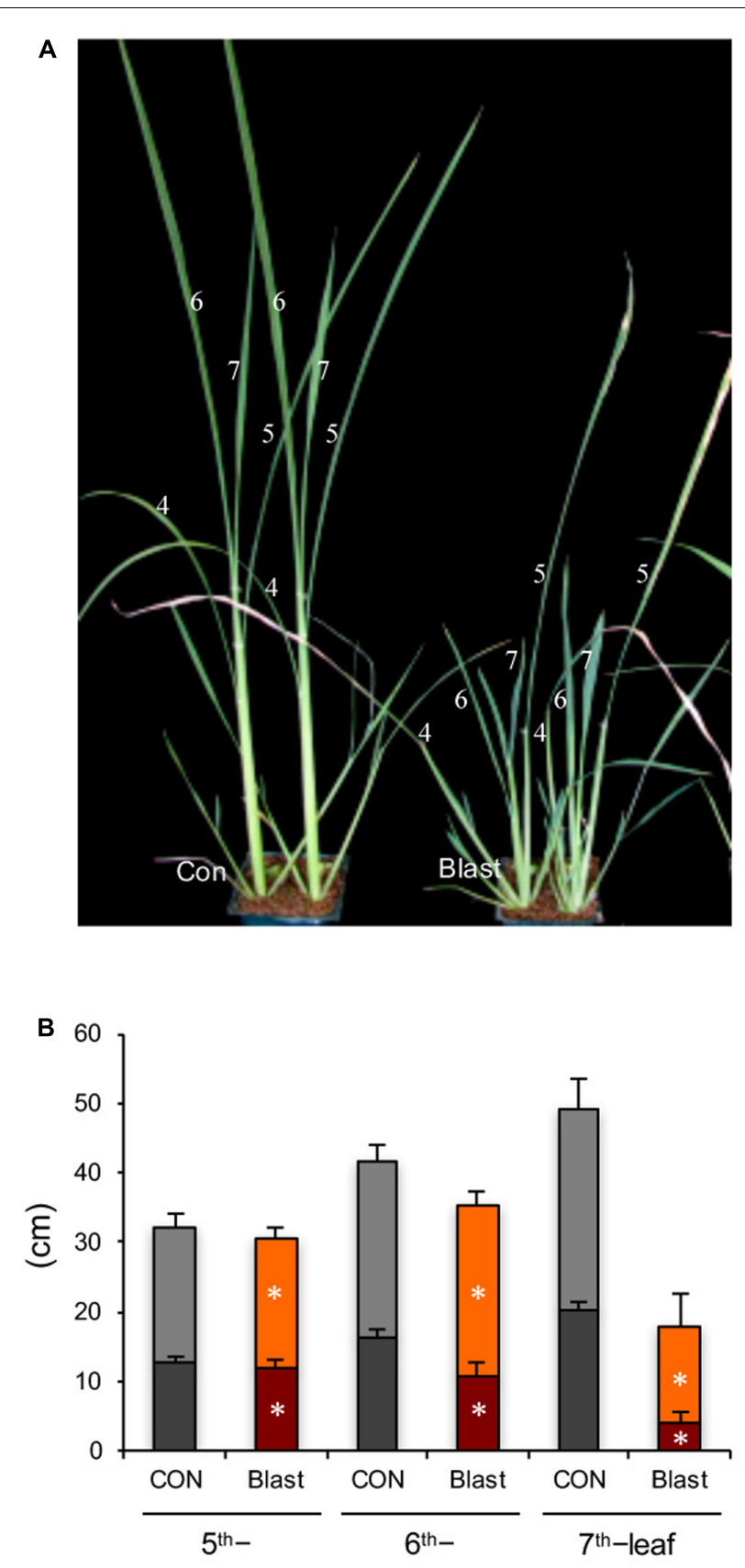

FIGURE 1 | Blast infection causes stunted growth of rice seedlings.

(A) Images of mock control (left) and blast-infected (right) rice seedlings. Rice seedlings at the four-leaf stage were inoculated with blast fungus $M$. oryzae (race 007.0), and the photograph was taken at 12-dpi. Numbers indicate leaf positions counted from shoot base. (B) Lengths of leaf blades (upper column) and leaf sheathes (bottom column) of fifth to seventh leaves, measured at 5 weeks post inoculation ( 5 wpi). Values are the means \pm standard errors; the asterisks indicate significant difference from the mock control plants (t-test, * indicates $P<0.01$ ).

(N) exhibited severe growth stunting; this was particularly true for both leaf blades and leaf sheathes, in $\mathrm{N}+2-3$ leaves (sixth and seventh leaves) (Figures 1A,B). As shown in Figure 2B, sixth leaf in the infected plants was greatly suppressed, and the distalhalf of most leaf blades was dead and dried. These results are consistent with previous observations by Tokunaga et al. (1959) and Yoshida et al. (1992). The growth inhibition was slight and negligible in $\mathrm{N}+4$ and upper leaves, consistent with observation by Yoshida et al. (1992).

\section{Cutting off Blast-Infected Leaf Blades Significantly Rescued the Growth Inhibition}

We hypothesized that a growth inhibition substance and/or signal is generated in the blast-infected leaves and transmitted to upper distal leaves. To determine this, we cut off the inoculated fourth leaf blades with a scissor in times at 1, 2, 3, $4,5,6$, and $7 \mathrm{dpi}$, and observed the effect on plant growth. The results show that cutting off the blast-infected leaf blades within $48 \mathrm{~h}$ after inoculation can significantly rescue the growth of plants (Figures 2A-C), particularly $\mathrm{N}+2-3$ leaves (sixth and seventh leaves) (Figures 2B,C). Cutting off blast-infected leaves after $48 \mathrm{~h}$ had little rescue effect on the leaf growth (Figure 2C).

\section{Jasmonate Signaling Is Activated in Blast-Infected Leaves}

We previously reported activations of SA, ABA, and CK signaling pathways in blast-infected leaf blades of rice seedlings (Jiang et al., 2010, 2013). To determine the changes in JA signaling pathway during blast infection, we analyzed expression of JA-responsive marker gene JAmyb (Lee et al., 2001) in blast-inoculated fourth leaf blades in a time course manner up to $6 \mathrm{dpi}$. We found that $J A m y b$ is significantly upregulated by blast infection within $2 \mathrm{dpi}$, and peaked at $4 \mathrm{dpi}$ and retained the upregulation until the end of the time course (Figure 3 ).

\section{Distal Changes in Phytohormone Signaling Pathways}

To obtain insight into the growth stunting by blast infection, we examined changes in phytohormone pathways in the sixth leaf $(\mathrm{N}+2)$ by expression analysis of hormone-responsive marker genes (Figure 4 and Supplementary Table 1). The results indicated activation of stress hormone pathways, and suppression of growth promoting hormone pathways in blast-infected plants (Figure 4).

Jasmonate-responsive genes, JAmyb (Lee et al., 2001) and OMT (Yoshii et al., 2010), and ABA-responsive genes, SalT (Rabbani et al., 2003) and OsWsil8 (Joshee et al., 1998), were significantly upregulated in response to blast infection at $3 \mathrm{dpi}$, and the expression levels were further increased at least until 6 dpi (Figures 4A-D). Interestingly, cutting off the inoculated fourth leaf blades reduced the induction of these genes (Figures 4A-D). Determination of JA and ABA contents in the sixth whole leaf at $3 \mathrm{dpi}$ showed no significant differences between uninoculated control and blast-infected plants (Supplementary Table 2).

By contrast, auxin-responsive genes, $A R F 1$ (Waller et al., 2002) and IAA9 (Jain et al., 2006), were downregulated in response 
A

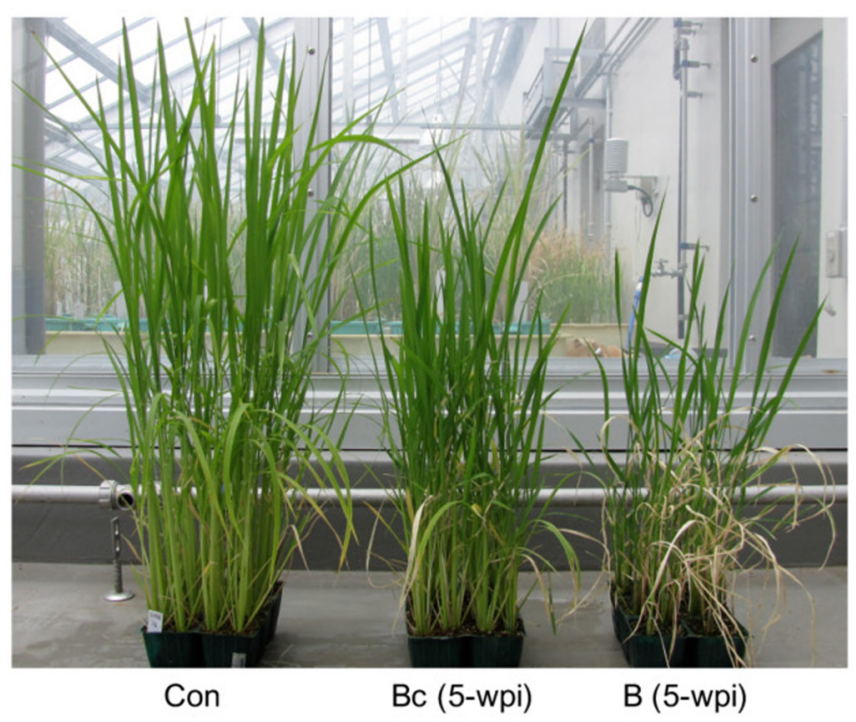

B

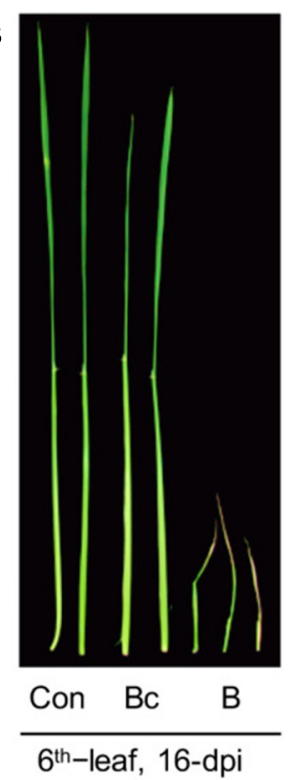

C

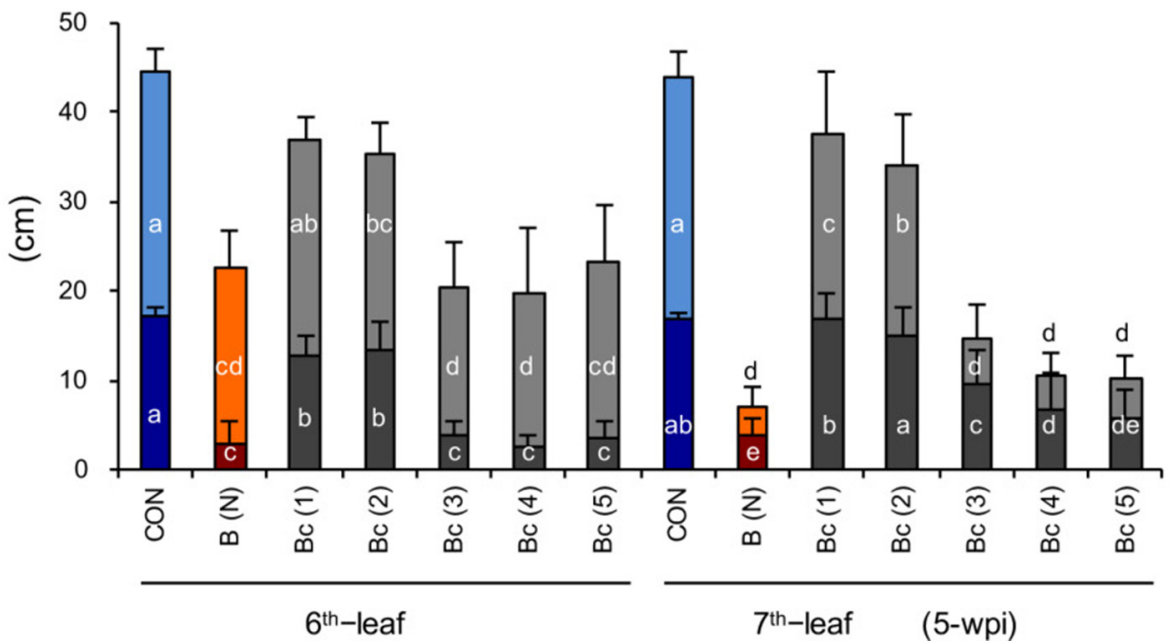

FIGURE 2 | Cutting off the blast-infected leaf blades significantly rescues the stunted growth of upper distal leaves. (A) Image of rice seedlings of mock control (Con, left), blast-infected (B, right), and cutting off blast-infected leaf blades (Bc, middle). Rice seedlings at the four-leaf stage were inoculated with blast fungus $M$. oryzae (race 007.0), and the photograph was taken at 5 wpi. (B) Close observation of the sixth leaf in mock control (Con, left), blast-infected (B, right), and cutting off blast-infected leaf blades (Bc, middle) at 16-dpi. (C) Lengths of leaf blades (upper column) and leaf sheathes (bottom column) of sixth and seventh leaves of rice seedlings shown in (A). Blast-infected leaf blades were cut off at dpi as indicated by numbers in parentheses. (N) depict no cutoff of leaf blades. Values are the means \pm standard errors; different letters on the bars indicate a significant difference $(P<0.05)$ based on Duncan's test.

to blast infection, and cutting off the inoculated leaves partially restored the downregulation (Figures 4E,F). On the other hand, a significant upregulation of GA-inactivation gene OsGA2ox3 (Sakai et al., 2003) and GA biosynthesis gene OsGA20ox1 (Toyomasu et al., 1997) were observed in blast-infected plants (Figures 4G,H). Cutting off the inoculated leaves partly reduced the upregulation (Figures 4G,H). OsGA2ox3 encodes an active GA 2-oxidase that inactivates bioactive GAs and its immediate precursors (Sakai et al., 2003); and OsGA20ox1 encodes a key enzyme for GA biosynthesis, whose expression is negatively regulated by GA (Toyomasu et al., 1997; Sakamoto et al.,
2001). These results indicate that signaling pathways of auxin and GA in the upper distal leaves are downregulated by blast infection.

Contrary to expectation, SA responsive marker genes WRKY45 (Shimono et al., 2007) and OsNPR1 (Sugano et al., 2010), and PR genes $O s P R 1 b$ and $P B Z 1$, were downregulated in response to blast infection (Figures 5A,B). Cutting off the infected leaf blades slightly restored expression of $O s P R 1 b$ and $P B Z 1$ in leaf blades, while no appreciable effect on WRKY45 and OsNPR1 was observed (Figures 5C,D). Expression levels of the genes were relatively low and had no 


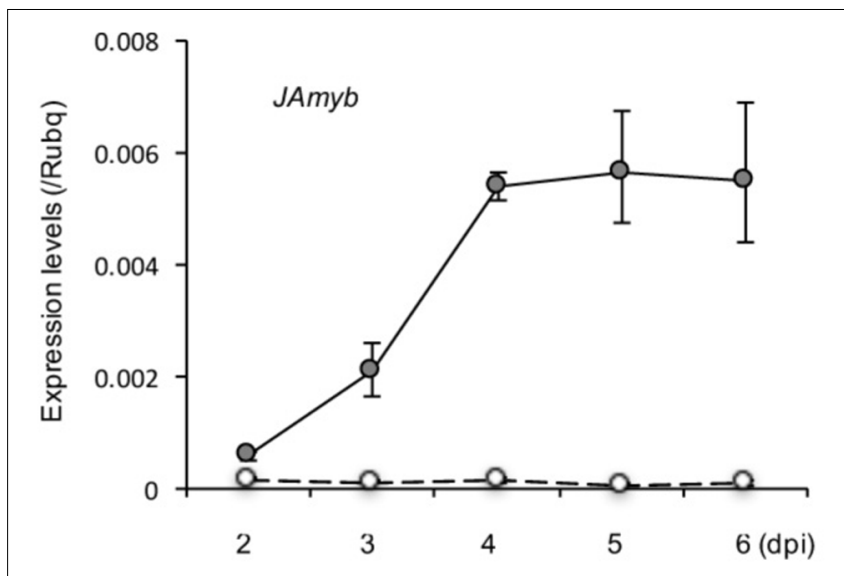

FIGURE 3 | Transcriptional induction of JA marker gene, JAmyb, in response to blast infection in the blast-infected leaf blades. Rice seedlings at the four-leaf stage were inoculated with blast fungus $M$. oryzae (race 007.0). Transcript levels of JA-responsive genes, JAmyb, were determined at the indicated time points (dpi) by qRT-PCR using Rubq1 as an internal control. Open and filled circles depict mock control and blast-inoculation, respectively. Mean values of three biological replicates with standard deviations are shown.

appreciable restoration by cutting off the infected leaf blades (Figures 5C,D).

\section{Cell Wall Related Genes Are Downregulated}

Cellulose synthase genes OsCESA5 and OsCESA6, cellulose synthase-like gene OsCSLA9, and expansin OsEXP1 and OsEXP15 were downregulated in response to blast infection, and cutting off the inoculated leaves partially reduced the downregulation (Figures 6A-E). These results are similar to those in stunted rice plants infected with RTSV (Budot et al., 2014).

\section{Reduction in JA Levels Partially Rescued the Growth Stunting}

As JA responsive marker genes were significantly upregulated in the stunted leaves (Figures $\mathbf{4 A , B}$ ), a rice mutant line cpm2 defective in the gene encoding allene oxide cyclase (OsAOC) (Biswas et al., 2003) was employed to investigate the possible association of JA signaling pathway with the growth stunting of blast-infected rice plants. The levels of endogenous JA and JA-isoleucine have been shown to be significantly reduced in cpm2 compared with that in its WT plants (Riemann et al., 2013). Compared with WT line (Nihonmasari), cpm2 plants exhibited more elongated leaves (Figure 7A). Blast infection resulted in reduction in leaf length of both cpm2 and its WT plants (Figure 7A). However, cpm2 had a remarkably higher relative leaf growth (leaf length in blast-infected plants relative to that in mock control plants) (Figure 7B), indicating that JA-reduction partially rescued the leaf growth inhibition caused by blast infection.

\section{Exogenous JA and ABA Caused Stunted Seedling Growth}

The effect of each phytohormone on plant growth was examined by root drenching of rice seedlings with each phytohormone at four-leaf stage and measuring leaf lengths of the fifth leaf of the seedlings, 4 weeks after the onset of treatments. As shown in Supplementary Figure 1, GA treatment promoted elongated growth. In contrast, JA and $\mathrm{ABA}$ treatments severely suppressed plant growth. The inhibition effects of leaf growth by JA and ABA were fairly similar to those by blast infection (Supplementary Figure 1B). Other phytohormones showed only minor effects on leaf growth (Supplementary Figure 1).

\section{DISCUSSION}

As early as several decades ago, it was observed that rice plants infected with blast fungus $M$. oryzae exhibit a severe growth inhibition in addition to formation of blast disease lesions at the infection sites on leaf blades (Tokunaga et al., 1959). The growth inhibition was manifested the most in successive upper two to three leaves counted from the infected leaf (Figure 1), consistent with previous reports (Tokunaga et al., 1959; Yoshida et al., 1992). This morphological symptom (Zurikomi) may be considered a consequence of a trade-off between growth and defense, in which rice plants prioritized defense reactions at the expense of plant growth at the time of infection. However, the underlying mechanism for this phenomenon has remained essentially elusive. It was previously suggested that excess accumulation of coumarin (Tamari and Kaji, 1959a,b) or ethylene evolution (Kozaka and Teraoka, 1977) in response to blast infection might be responsible for the growth inhibition; however, these suggestions were not supported in later studies (Satoh and Kozaka, 1966, 1971; Yoshida et al., 1992). In this study, we found that cutting off the blast-infected leaf blade within 2 dpi significantly rescued the growth inhibition of upper distal leaves (Figure 2). This suggests that a yet unknown inhibitory substance(s) and/or signal is generated in the blast-infected sites and transmitted to upper uninfected distal leaves, where it induced growth inhibition. In the upper distal leaves, JA- and ABA-pathways were upregulated, whereas auxin- and GA-pathways were downregulated (Figure 4). It has been shown that JA and ABA negatively impact plant growth, in contrast to auxin and GAs, which promote plant growth (Swiatek et al., 2003; Xiang et al., 2008; Zhang and Turner, 2008; Yang et al., 2012; Liu et al., 2015; Hibara et al., 2016). The GA-responsive cell wall related genes (Budot et al., 2014) were also significantly downregulated (Figure 6). Further, the JA-deficient rice mutant cpm2 showed a less pronounced leaf growth inhibition compared with its WT plants upon blast infection (Figure 7). In addition, treatment of rice seedlings with JA and ABA resulted in stunted growth resembling blast infection (Supplementary Figure 1). Taken together, these results strongly suggest that an inhibitory substance(s) and/or signal(s) generated in the blast-infected leaves activated JA and $\mathrm{ABA}$, and suppressed GA and auxin signaling pathways in the upper distal leaves, which in turn resulted in growth 

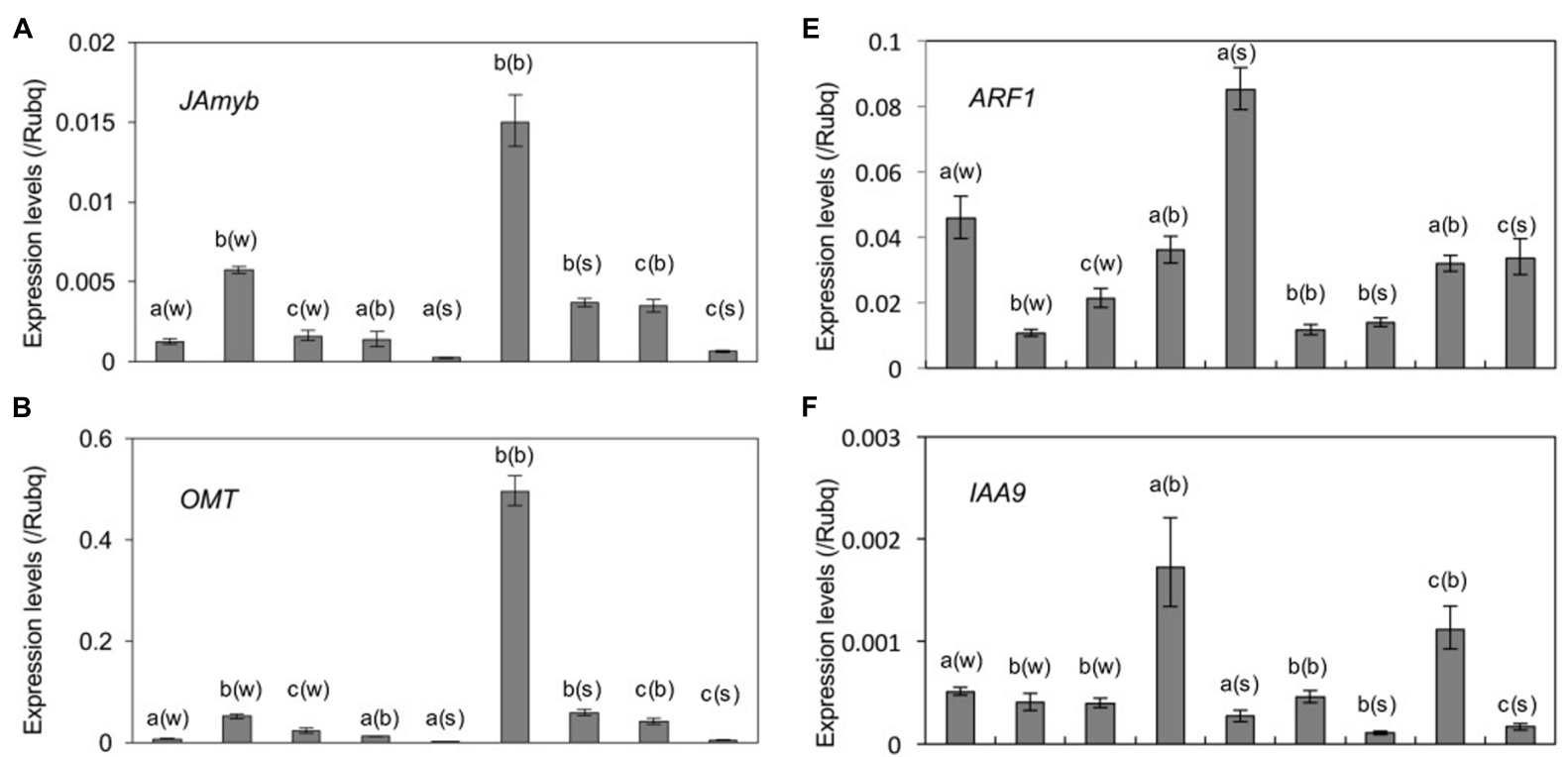

$\mathbf{F}$
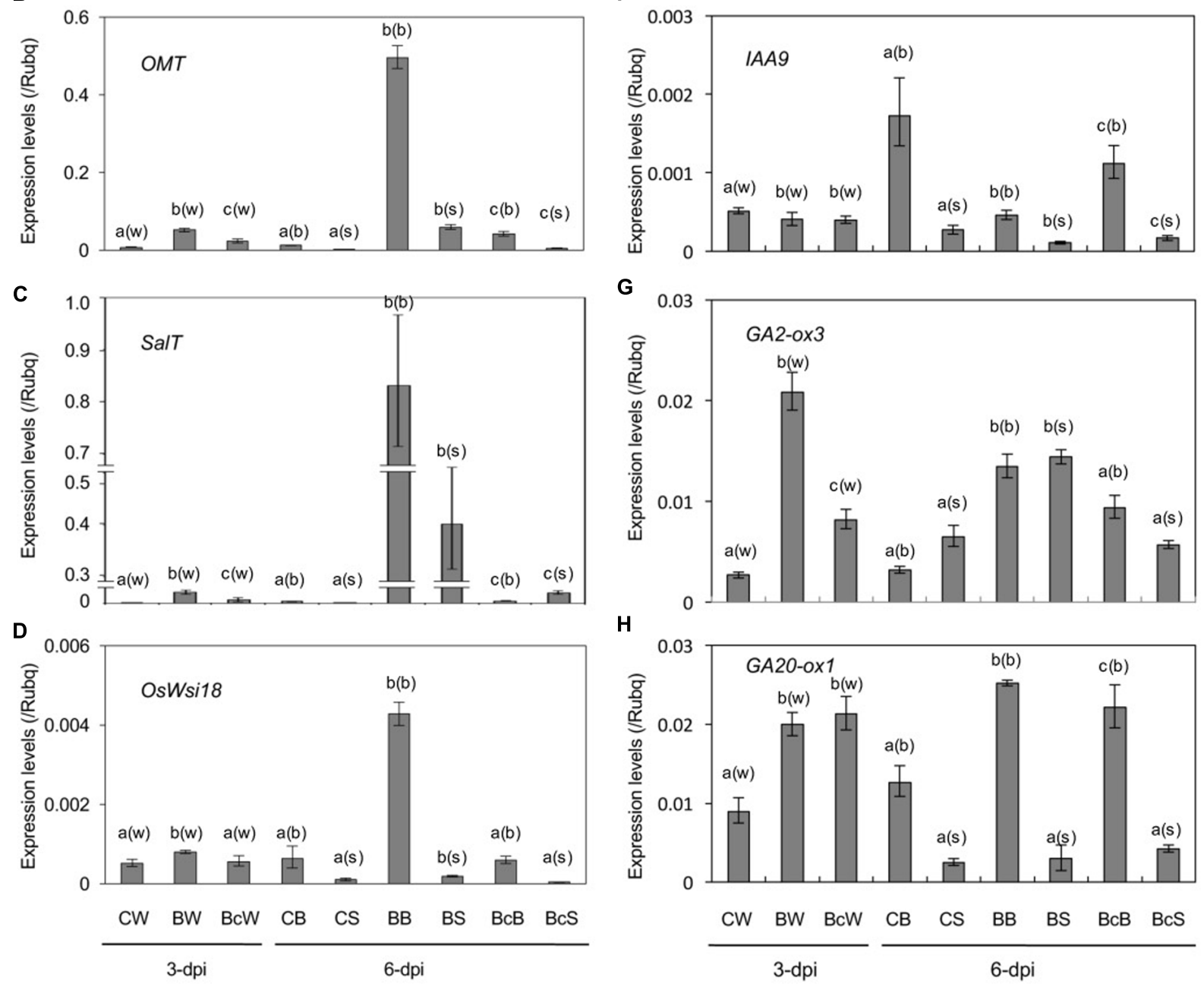

FIGURE 4 | Expression analysis of marker genes for JA (A,B), ABA (C,D), IAA (E,F), and GA (G,H) in the sixth leaf of mock control (CW, CB, and CS), blast-infected (BW, BB, and BS), and cutting off blast-infected leaf blades (BcW, BcB, and BcS). Rice seedlings at four-leaf stage were blast-inoculated, and half of them were subjected to cutting off the inoculated fourth leaf blades at 2-dpi. Whole sixth leaf from every treatment was collected at 3-dpi (CW, BW, and BcW), and leaf blades (CB, BB, and BcB) and leaf sheathes (CS, BS, and BcS) separately at 6-dpi. Values are the means \pm standard errors. Different letters above bars indicate a significant difference $(P<0.05)$ based on Duncan's test; (w): for whole leaves, (b): for leaf blades, (s): for leaf sheaths.

stunting of the leaves. These findings provide new insights into the controlling mechanism of growth-defense balance in rice plants.

It has been reported that JA antagonistically interacts with the GA signaling cascade to prioritize defense over growth upon pathogen attacks in both Arabidopsis and rice (Yang et al.,
2012). It was shown that Arabidopsis and rice coil mutants, defective in JA perception, exhibited GA hypersensitivity; JA delayed GA-mediated degradation of DELLA protein, and conversely the DELLA mutant was less sensitive to JA in terms of growth inhibition (Yang et al., 2012). Our previous and present studies showed that the signaling pathways of 

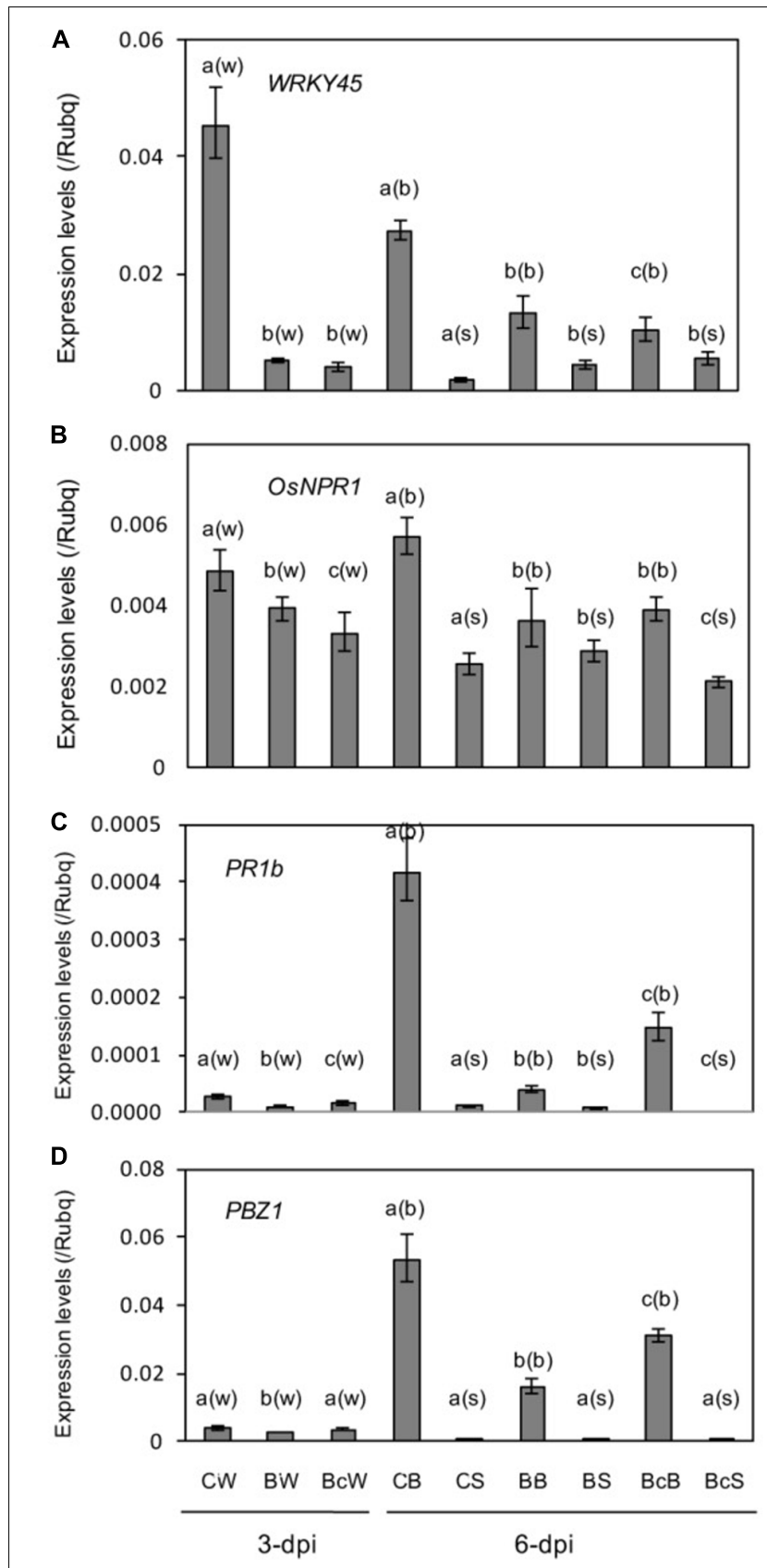

FIGURE 5 | (A-D) Expression analysis of SA responsive genes and PR genes in the sixth leaf as described in Figure 4. Values are the means \pm standard errors. Different letters above bars indicate a significant difference $(P<0.05)$ based on Duncan's test; (w): for whole leaves, (b): for leaf blades, (s): for leaf sheaths.

both JA (Figure 3) and ABA (Jiang et al., 2010) are activated in blast-infected leaves. However, they differed in induction time: JA within $2 \mathrm{dpi}$, whereas $\mathrm{ABA}$ at $3 \mathrm{dpi}$. Taking these results together with the data shown in Figures 2, 4-7, it is tempting to speculate that JA may possibly take a role in signal transmission from blast-infected sites to upper distal leaves. Naturally, this hypothesis needs to be validated in future studies.

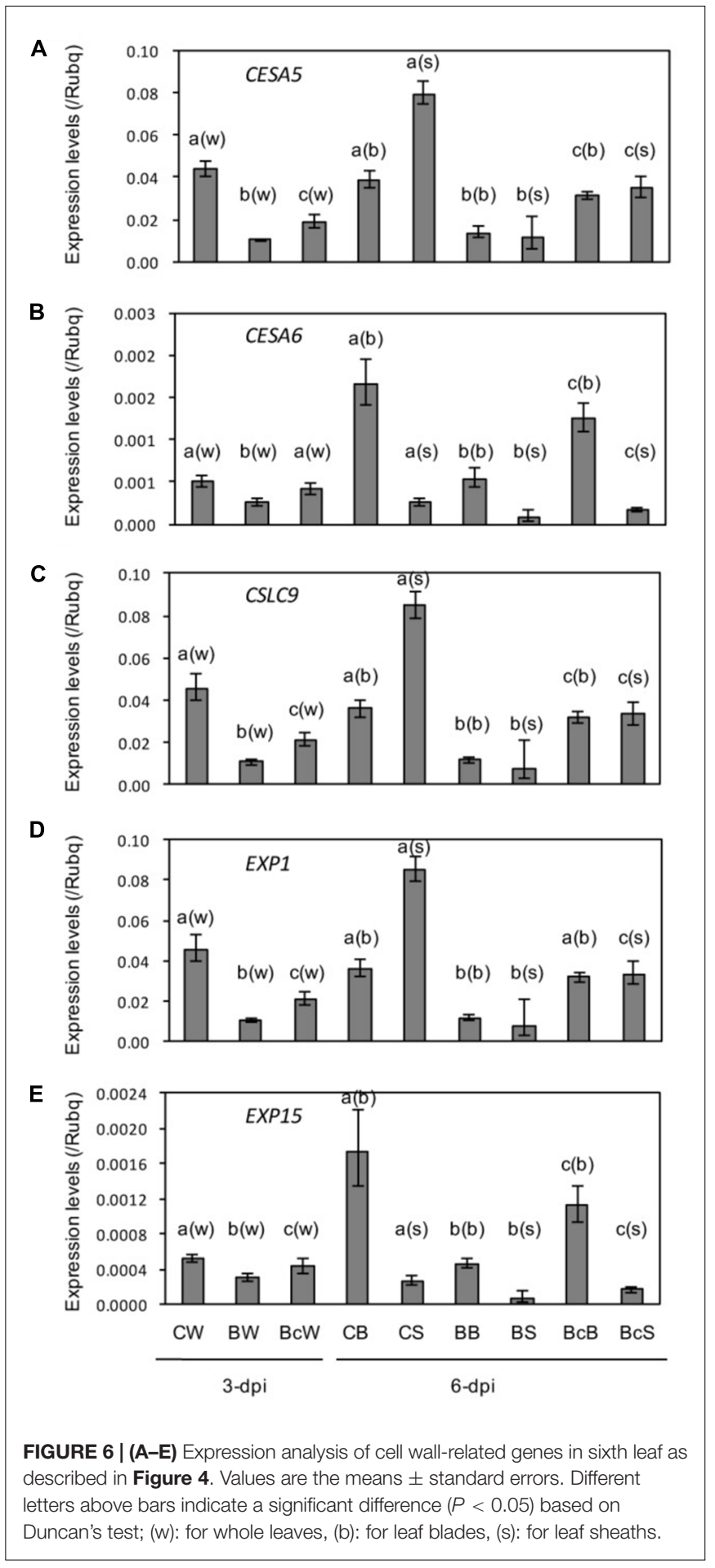

Moreover, only a partial growth restoration in blast-infected cpm2 seedlings (Figure 7) indicates the existence of additional factor(s) functioning in the growth stunting. In this context, ABA may also participate in the growth inhibition in later stages following the JA. Meanwhile, it is also possible that the partial growth restoration in $c p m 2$ seedlings is due to remaining quantities of JA (Riemann et al., 2013). The mechanism of 

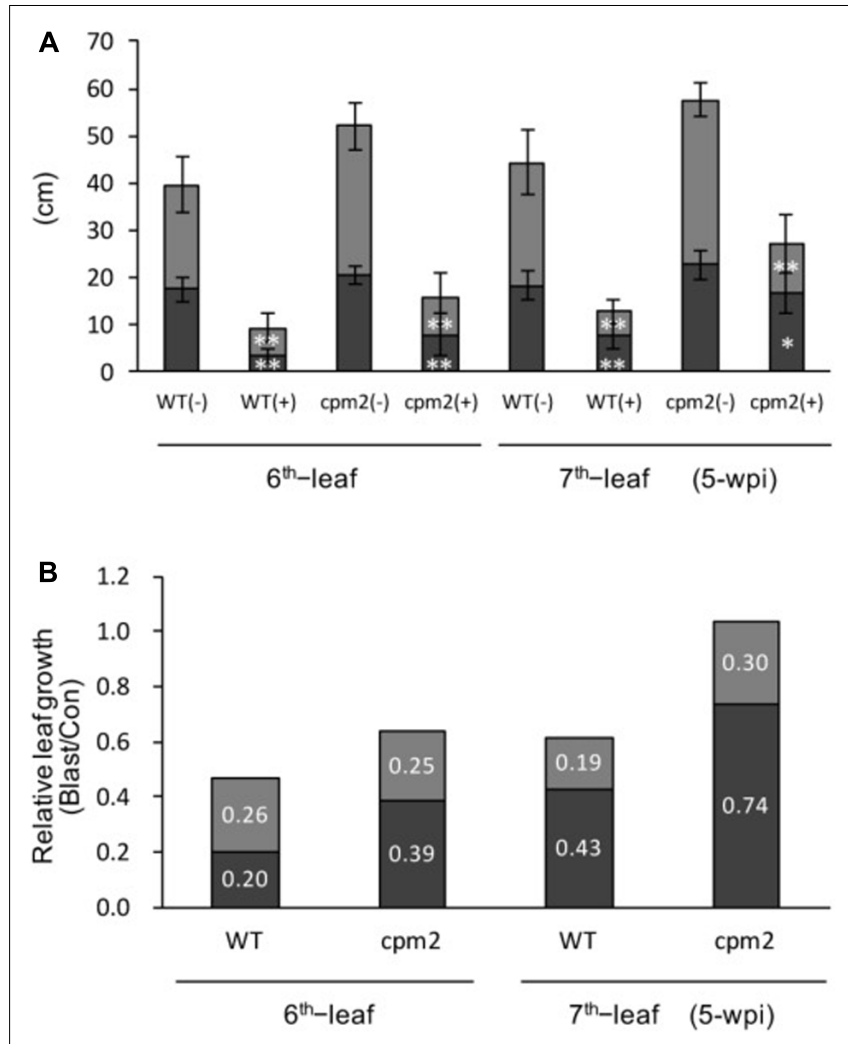

FIGURE 7 | Growth inhibition by blast infection is partially rescued in JA-deficient mutant cpm2. (A) Rice seedlings at the four-leaf stage were inoculated with blast fungus $M$. oryzae (race 007.0), and lengths of leaf blades (upper column) and leaf sheathes (bottom column) of sixth and seventh leaves were measured at 5-wpi. WT: wild type control of cpm2; $(-)=$ mock control; $(+)$ = blast-infected. Values are the means \pm standard errors; the asterisks indicate significant difference from the mock control plants ( $t$-test, * and ** indicate $P<0.05$ and 0.01 , respectively). (B) Relative growth of leaf blades (upper columns) and leaf sheaths (bottom columns) of sixth and seventh leaves were expressed as leaf length in blast-infected plants relative to that in mock control plants.

distal activation of JA- and ABA-signaling pathways in response to blast infection is unknown. Determination of JA and ABA contents showed no appreciable changes either in blast-infected rice leaves (Schweizer et al., 1997; Jiang et al., 2013) or in upper distal leaves (Supplementary Table 2), even though the marker genes were activated in both the local (Schweizer et al., 1997; Jiang et al., 2010) and distal sites (Figure 4). A similar phenomenon was also observed for SA, in which blast infection of rice seedlings induced SA responsive genes without a concomitant increase in endogenous SA levels (Silverman et al., 1995). A possible explanation for these observations may be the intracellular relocalization or releasing from sequestration of these phytohormones in response to blast fungus infection. Alternatively, the possibility that a local increase of the phytohormones at the infection spots was technically difficult to detect cannot be excluded.

Stunted or dwarfed plant growth is also observed in rice plants infected with several disease-causing viruses, which has been associated with suppression of GA and/or auxin signaling cascades and expression of genes related to cell wall synthesis and expansion (Satoh et al., 2010, 2011, 2013; Budot et al., 2014). It has also been shown that the defense master regulator OsNPR1 attenuates rice plant growth by repressing auxin signaling pathway ( $\mathrm{Li}$ et al., 2016). Consistent with these, we found significant reduction in auxin and GA pathways (Figures 4E-H) as well as in expression levels of cell wall related genes (Figure 6) in the upper distal leaves of blast-infected rice seedlings. This indicates that the reduction in auxin and GA pathways also plays a causative role in the growth stunting. Whether the reduction in auxin and GA pathways is associated with the upregulation of JA and ABA pathways remains to be elucidated.

Unexpectedly, SA responsive marker genes WRKY45 and OsNPR1, and PR genes OsPR1b and PBZ1 are downregulated in response to blast infection in the upper distal leaves (Figure 5). This may imply that rice plants prioritize the defense against infecting pathogen over the distal uninfected tissues as well in order to efficiently cope with the life-threatening situation. There have been several reports that priming of rice seedlings by pre-inoculation with an avirulent $M$. oryzae isolate enhanced resistance following infection by virulent isolates (Manandhar et al., 1998; Ashizawa et al., 2005; Yasuda et al., 2008; Filippi et al., 2014). However, to our knowledge, no study has yet explored the systemic defense regulation during rice-pathogen ( $M$. oryzae) interaction. The downregulation of the WRKY45 and OsNPR1 may be due to the activation of $\mathrm{ABA}$, as ABA negatively impacts on SA signaling pathway (Jiang et al., 2010; Sugano et al., 2010). It would be interesting to investigate how blast resistance changes in relation to alterations of phytohormone pathways in distal tissues upon blast infection.

In summary, we showed that a yet unknown inhibitory substance(s) and/or signal(s) is generated in the M. oryzaeinfected leaves and transmitted to the upper distal leaves, where it causes growth stunting through activation of JA and ABA, and suppression of GA, auxin, and SA signaling pathways, to mediate the prioritizing of defense responses against pathogen attack over growth in rice plants.

\section{AUTHOR CONTRIBUTIONS}

C-JJ and Z-WL conceived and designed the study, X-LL, X-QL, $\mathrm{HZ}$, and Y-JY conducted the experiments, collected and analyzed the data, and C-JJ wrote the manuscript.

\section{FUNDING}

This work was supported by a Grant-in-Aid for Scientific Research (number 22570057) from the Ministry of Education, Culture, Sports, Science and Technology, Japan, Chinese Academy of Sciences STS network Foundation (No. KFJ-SWSTS-141-01) and the National Natural Science Foundation of China (31370306). 


\section{ACKNOWLEDGMENT}

We thank Prof. Moritoshi Iino (Osaka City University, Japan) for providing cpr2 mutant, Dr. Mikiko Kojima and Dr. Hitoshi Sakakibara (RIKEN, Japan) for measurement of jasmonic acid.

\section{REFERENCES}

Akagi, A., Jiang, C.-J., and Takatsuji, H. (2015). Magnaporthe oryzae inoculation of rice seedlings by spraying with a spore suspension. Bio-protocol 5:e1486. doi: 10.21769/BioProtoc. 1486

Ashizawa, T., Zenbayashi, K., and Sonoda, R. (2005). Effects of preinoculation with an avirulent isolate of Pyricularia grisea on infection and development of leaf blast lesions caused by virulent isolates on near-isogenic lines of Sasanishiki rice. J. Gen. Plant Pathol. 71, 345-350. doi: 10.1007/s10327-005-0216-1

Babu, R. M., Sajeena, A., Vijayasamundeeswari, A., Sreedhar, A., Vidhyasekeran, P., and Reddy, M. S. (2003). Induction of bacterial blight (Xanthomonas oryzae pv. oryzae) resistance in rice by treatment with acibenzolar-S-methyl. Ann. Appl. Biol. 143, 333-340. doi: 10.1111/j.1744-7348.2003.tb00302.x

Bailey, T. A., Zhou, X., Chen, J., and Yang, Y. (2009). "Role of ethylene, abscisic acid and MAP kinase pathways in rice blast resistance," in Advances in Genetics, Genomics and Control of Rice Blast Disease, eds G. L. Wang and B. Valent (Dordrecht: Springer), 185-190. doi: 10.1007/978-1-4020-9500-9_19

Biswas, K. K., Neumann, R., Haga, K., Yatoh, O., and Iino, M. (2003). Photomorphogenesis of rice seedlings: a mutant impaired in phytochromemediated inhibition of coleoptile growth. Plant Cell Physiol. 44, 242-254. doi: $10.1093 / \mathrm{pcp} / \mathrm{pcg} 040$

Brooks, D. B., Bender, C. L., and Kunkel, B. N. (2005). The Pseudomonas syringae phytotoxin coronatine promotes virulence by overcoming salicylic acid-dependent defences in Arabidopsis thaliana. Mol. Plant Pathol. 6, 629-639. doi: 10.1111/j.1364-3703.2005.00311.x

Budot, B. O., Encabo, J. R., Ambita, I. D. V., Atienza-Grande, G. A., Satoh, K., Kondoh, H., et al. (2014). Suppression of cell wall-related genes associated with stunting of Oryza glaberrima infected with Rice tungro spherical virus. Front. Microbiol. 5:26. doi: 10.3389/fmicb.2014.00026

Ding, X., Cao, Y., Huang, L., Zhao, J., Xu, C., Li, X., et al. (2008). Activation of the indole-3-acetic acid-amido synthetase GH3-8 suppresses expansin expression and promotes salicylate- and jasmonate-independent basal immunity in rice. Plant Cell 20, 228-240. doi: 10.1105/tpc.107.055657

Domingo, C., Andres, F., Tharreau, D., Iglesias, D. J., and Talon, M. (2009). Constitutive expression of OsGH3.1 reduces auxin content and enhances defense response and resistance to a fungal pathogen in rice. Mol. Plant Microbe Interact. 22, 201-210. doi: 10.1094/MPMI-22-2-0201

Filippi, M., da Silva, G., da Silva-Lobo, V., Viana, H., Côrtes, M. D. C., and Prabhu, A. (2014). Induction of resistance to rice leaf blast by avirulent isolates of Magnaporthe oryzae. J. Agricul. Environ. Sci. 57, 388-395. doi: 10.3389/fpls. 2016.01140

Fu, J., Liu, H., Li, Y., Yu, H., Li, X., Xiao, J., et al. (2011). Manipulating broad-spectrum disease resistance by suppressing pathogen-induced auxin accumulation in rice. Plant Physiol. 155, 589-602. doi: 10.1104/pp.110.163774

Garg, R., Tyagi, A. K., and Jain, M. (2012). Microarray analysis reveals overlapping and specific transcriptional responses to different plant hormones in rice. Plant Signal. Behav. 7, 951-956. doi: 10.4161/psb.20910

Helliwell, E. E., Wang, Q., and Yang, Y. (2013). Transgenic rice with inducible ethylene production exhibits broad-spectrum disease resistance to the fungal pathogens Magnaporthe oryzae and Rhizoctonia solani. Plant Biotechnol. J. 11, 33-42. doi: 10.1111/pbi.12004

Hibara, K., Isono, M., Mimura, M., Sentoku, N., Kojima, M., Sakakibara, H., et al. (2016). Jasmonate regulates juvenile-to-adult phase transition in rice. Development 143, 3407-3416. doi: 10.1242/dev.138602

Huot, B., Yao, J., Montgomery, B. L., and He, S. Y. (2014). Growth-defense tradeoffs in plants: a balancing act to optimize fitness. Mol. Plant 7, 1267-1287. doi: $10.1093 / \mathrm{mp} / \mathrm{ssu} 049$

Iwai, T., Miyasaka, A., Seo, S., and Ohashi, Y. (2006). Contribution of ethylene biosynthesis for resistance to blast fungus infection in young rice plants. Plant Physiol. 142, 1202-1215. doi: 10.1104/pp.106.085258

\section{SUPPLEMENTARY MATERIAL}

The Supplementary Material for this article can be found online at: http://journal.frontiersin.org/article/10.3389/fpls.2017.01558/ full\#supplementary-material

Jain, M., Kaur, N., Garg, R., Thakur, J. K., Tyagi, A. K., and Khurana, J. P. (2006). Structure and expression analysis of early auxin-responsive Aux/IAA gene family in rice (Oryza sativa). Funct. Integr. Genomics 6, 47-59. doi: 10.1007/ s10142-005-0005-0

Jiang, C. J., Shimono, M., Maeda, S., Inoue, H., Mori, M., Hasegawa, M., et al. (2009). Suppression of the rice fatty-acid desaturase gene OsSSI2 enhances resistance to blast and leaf blight diseases in rice. Mol. Plant Microbe Interact. 22, 820-829. doi: 10.1094/MPMI-22-7-0820

Jiang, C. J., Shimono, M., Sugano, S., Kojima, M., Liu, X., Inoue, H., et al. (2013). Cytokinins act synergistically with salicylic acid to activate defense gene expression in rice. Mol. Plant Microbe Interact. 26, 287-296. doi: 10.1094/ MPMI-06-12-0152-R

Jiang, C. J., Shimono, M., Sugano, S., Kojima, M., Yazawa, K., Yoshida, R., et al. (2010). Abscisic acid interacts antagonistically with salicylic acid signaling pathway in rice-Magnaporthe grisea interaction. Mol. Plant Microbe Interact. 23, 791-798. doi: 10.1094/MPMI-23-6-0791

Joshee, N., Kisaka, H., and Kitagawa, Y. (1998). Isolation and characterization of a water stress-specific genomic gene, pwsi 18, from rice. Plant Cell Physiol. 39, 64-72. doi: 10.1093/oxfordjournals.pcp.a029290

Kazan, K., and Lyons, R. (2014). Intervention of phytohormone pathways by pathogen effectors. Plant Cell 26, 2285-2309. doi: 10.1105/tpc.114. 125419

Kojima, M., and Sakakibara, H. (2012). Highly sensitive high-throughput profiling of six phytohormones using MS-probe modification and liquid chromatography-tandem mass spectrometry. Methods Mol. Biol. 918, 151-164. doi: 10.1007/978-1-61779-995-2_11

Kozaka, T., and Teraoka, T. (1977). Ethylene evolution by rice plants infected with Pyricularia oryzae Cav. in relation to the stunting of diseased plants. Jpn. J. Phytopathol. 43, 549-556. doi: 10.3186/jjphytopath.43.549

Laurie-Berry, N., Joardar, V., Street, I. H., and Kunkel, B. N. (2006). The Arabidopsis thaliana JASMONATE INSENSITIVE 1 gene is required for suppression of salicylic acid-dependent defenses during infection by Pseudomonas syringae. Mol. Plant Microbe Interact. 19, 789-800. doi: 10.1094/ MPMI-19-0789

Lee, M. W., Qi, M., and Yang, Y. (2001). A novel jasmonic acid-inducible rice myb gene associates with fungal infection and host cell death. Mol. Plant Microbe Interact. 14, 527-535. doi: 10.1094/MPMI.2001.14.4.527

Li, X., Yang, D., Sun, L., Li, Q., Mao, B., and He, Z. (2016). The systemic acquired resistance regulator OsNPR1 attenuates growth by repressing auxin signaling and promoting IAA-amido synthase expression. Plant Physiol. 172, 546-558. doi: 10.1104/pp.16.00129

Liu, Z., Zhang, S., Sun, N., Liu, H., Zhao, Y., Liang, Y., et al. (2015). Functional diversity of jasmonates in rice. Rice 8:42. doi: 10.1186/s12284-015-0042-9

Ma, K. W., and Ma, W. B. (2016). Phytohormone pathways as targets of pathogens to facilitate infection. Plant Mol. Biol. 91, 713-725. doi: 10.1007/s11103-0160452-0

Manandhar, H. K., Jorgensen, H. J. L., Mathur, S. B., and Smedegaard-Petersen, V. (1998). Suppression of rice blast by preinoculation with avirulent Pyricularia oryzae and the nonrice pathogen Bipolaris sorokiniana. Plant Pathol. 88, 735-739. doi: 10.1094/Phyto.1998.88.7.735

Mei, C., Qi, M., Sheng, G., and Yang, Y. (2006). Inducible overexpression of a rice allene oxide synthase gene increases the endogenous jasmonic acid level, PR gene expression, and host resistance to fungal infection. Mol. Plant Microbe Interact. 19, 1127-1137. doi: 10.1094/MPMI-19-1127

Meldau, S., and Baldwin, I. T. (2013). Just in time: circadian defense patterns and the optimal defense hypothesis. Plant Signal. Behav. 8:e24410. doi: 10.4161/psb. 24410

Meldau, S., Erb, M., and Baldwin, I. T. (2012). Defence on demand: mechanisms behind optimal defence patterns. Ann. Bot. 110, 1503-1514. doi: 10.1093/aob/ $\operatorname{mcs} 212$ 
Pajerowska-Mukhtar, K. M., Wang, W., Tada, Y., Oka, N., Tucker, C. L., Fonseca, J. P., et al. (2012). The HSF-like transcription factor TBF1 is a major molecular switch for plant growth-to-defense transition. Curr. Biol. 22, 103-112. doi: 10.1016/j.cub.2011.12.015

Rabbani, M. A., Maruyama, K., Abe, H., Khan, M. A., Katsura, K., Ito, Y., et al. (2003). Monitoring expression profiles of rice genes under cold, drought, and high-salinity stresses and abscisic acid application using cDNA microarray and RNA gel-blot analyses. Plant Physiol. 133, 1755-1767. doi: 10.1104/pp.103. 025742

Riemann, M., Haga, K., Shimizu, T., Okada, K., Ando, S., Mochizuki, S., et al. (2013). Identification of rice allene oxide cyclase mutants and the function of jasmonate for defence against Magnaporthe oryzae. Plant J. 74, 226-238. doi: $10.1111 /$ tpj. 12115

Robert-Seilaniantz, A., Grant, M., and Jones, J. D. (2011). Hormone crosstalk in plant disease and defense: more than just jasmonate-salicylate antagonism. Annu. Rev. Phytopathol. 49, 317-343. doi: 10.1146/annurev-phyto-073009114447

Rohilla, R., Singh, U. S., and Singh, R. L. (2002). Mode of action of acibenzolarS-methyl against sheath blight of rice, caused by Rhizoctonia solani Kuhn. Pest Manag. Sci. 58, 63-69. doi: 10.1002/ps.423

Sakai, M., Sakamoto, T., Saito, T., Matsuoka, M., Tanaka, H., and Kobayashi, M. (2003). Expression of novel rice gibberellin 2-oxidase gene is under homeostatic regulation by biologically active gibberellins. J. Plant Res. 116, 161-164. doi: 10.1007/s10265-003-0080-z

Sakamoto, T., Kobayashi, M., Itoh, H., Tagiri, A., Kayano, T., Tanaka, H., et al. (2001). Expression of a gibberellin 2-oxidase gene around the shoot apex is related to phase transition in rice. Plant Physiol. 125, 1508-1516. doi: 10.1104/ pp.125.3.1508

Satoh, K., Kondoh, H., Sasaya, T., Shimizu, T., Choi, I. R., Omura, T., et al. (2010). Selective modification of rice (Oryza sativa) gene expression by rice stripe virus infection. J. Gen. Virol. 91, 294-305. doi: 10.1099/vir.0.015990-0

Satoh, K., Shimizu, T., Kondoh, H., Hiraguri, A., Sasaya, T., Choi, I. R., et al. (2011). Relationship between symptoms and gene expression induced by the infection of three strains of rice dwarf virus. PLOS ONE 6:e18094. doi: 10.1371/journal. pone.0018094

Satoh, K., Yoneyama, K., Kondoh, H., Shimizu, T., Sasaya, T., Choi, I. R., et al. (2013). Relationship between gene responses and symptoms induced by Rice grassy stunt virus. Front. Microbiol. 4:313. doi: 10.3389/fmicb.2013.00313

Satoh, Y., and Kozaka, T. (1966). Growth inhibitory substance in blast diseased rice plants (I). Ann. Phytopath. Soc. Japan 32, 74.

Satoh, Y., and Kozaka, T. (1971). Growth inhibitory substance in blast diseased rice plants (II). Ann. Phytopath. Soc. Japan 37, 162.

Schweizer, P., Buchala, A., Silverman, P., Seskar, M., Raskin, I., and Metraux, J. P. (1997). Jasmonate-inducible genes are activated in rice by pathogen attack without a concomitant increase in endogenous jasmonic acid levels. Plant Physiol. 114, 79-88. doi: 10.1104/pp.114.1.79

Schweizer, P., Schlagenhauf, E., Schaffrath, U., and Dudler, R. (1999). Different patterns of host genes are induced in rice by Pseudomonas syringae, a biological inducer of resistance, and the chemical inducer benzothiadiazole (BTH). Eur. J. Plant Pathol. 105, 659-665. doi: 10.1023/A:1008791223608

Seo, S., Mitsuhara, I., Feng, J., Iwai, T., Hasegawa, M., and Ohashi, Y. (2011). Cyanide, a coproduct of plant hormone ethylene biosynthesis, contributes to the resistance of rice to blast fungus. Plant Physiol. 155, 502-514. doi: 10.1104/ pp.110.162412

Shimono, M., Sugano, S., Nakayama, A., Jiang, C. J., Ono, K., Toki, S., et al. (2007). Rice WRKY45 plays a crucial role in benzothiadiazole-inducible blast resistance. Plant Cell 19, 2064-2076. doi: 10.1105/tpc.106.046250

Silverman, P., Seskar, M., Kanter, D., Schweizer, P., Metraux, J. P., and Raskin, I. (1995). Salicylic acid in rice: biosynthesis, conjugation, and possible role. Plant Physiol. 108, 633-639. doi: 10.1104/pp.108.2.633

Sugano, S., Jiang, C. J., Miyazawa, S., Masumoto, C., Yazawa, K., Hayashi, N., et al. (2010). Role of OsNPR1 in rice defense program as revealed by genome-wide expression analysis. Plant Mol. Biol. 74, 549-562. doi: 10.1007/s11103-0109695-3

Swiatek, A., Azmi, A., Witters, E., and Van Onckelen, H. (2003). Stress messengers jasmonic acid and abscisic acid negatively regulate plant cell cycle. Bulg. J. Plant Physiol. 29, 172-178.
Takatsuji, H. (2017). Regulating tradeoffs to improve rice production. Front. Plant Sci. 8:171. doi: 10.3389/fpls.2017.00171

Takatsuji, H., and Jiang, C.-J. (2014). "Plant hormone crosstalks under biotic stresses," in Phytohormones: A Window to Metabolism, Signaling and Biotechnological Applications, eds L. S. Tran and S. Pal (New York, NY: Springer), 323-350. doi: 10.1007/978-1-4939-0491-4_11

Tamaoki, D., Seo, S., Yamada, S., Kano, A., Miyamoto, A., Shishido, H., et al. (2013). Jasmonic acid and salicylic acid activate a common defense system in rice. Plant Signal. Behav. 8:e24260. doi: 10.4161/psb.24260

Tamari, K., and Kaji, J. (1959a). Biochemical studies on the blast disease of rice plant (XII). Nippon Nogeikagaku Kaishi 33, 178-180. doi: 10.1271/ nogeikagaku1924.33.3_178

Tamari, K., and Kaji, J. (1959b). Biochemical studies on the blast disease of rice plant (XIII). Nippon Nogeikagaku Kaishi 33, 181-183. doi: 10.1271/ nogeikagaku1924.33.3_181

Tanaka, N., Matsuoka, M., Kitano, H., Asano, T., Kaku, H., and Komatsu, S. (2006). gid1, a gibberellin-insensitive dwarf mutant, shows altered regulation of probenazole-inducible protein (PBZ1) in response to cold stress and pathogen attack. Plant Cell Environ. 29, 619-631. doi: 10.1111/j.1365-3040.2005. 01441.x

Tokunaga, Y., Furuta, T., and Sasaki, T. (1959). Influences of blast disease on the growth and physiology of rice plant. Tohoku J. Agric. Res. 17, $102-136$.

Toyomasu, T., Kawaide, H., Sekimoto, H., Numers, C. V., Phillips, A. L., Hedden, P., et al. (1997). Cloning and characterization of a cDNA encoding gibberellin 20-oxidase from rice (Oryza sativa) seedlings. Physiol. Plant 99, 111-118. doi: 10.1111/j.1399-3054.1997.tb03438.x

Waller, F., Furuya, M., and Nick, P. (2002). OsARF1, an auxin response factor from rice, is auxin-regulated and classifies as a primary auxin responsive gene. Plant Mol. Biol. 50, 415-425. doi: 10.1023/A:1019818110761

Wang, D., Amornsiripanitch, N., and Dong, X. (2006). A genomic approach to identify regulatory nodes in the transcriptional network of systemic acquired resistance in plants. PLoS Pathog. 2:e123. doi: 10.1371/journal.ppat.002 0123

Xiang, Y., Tang, N., Du, H., Ye, H. Y., and Xiong, L. Z. (2008). Characterization of $O s b Z I P 23$ as a key player of the basic leucine zipper transcription factor family for conferring abscisic acid sensitivity and salinity and drought tolerance in rice. Plant Physiol. 148, 1938-1952. doi: 10.1104/pp.108.12 8199

Yamada, S., Kano, A., Tamaoki, D., Miyamoto, A., Shishido, H., Miyoshi, S., et al. (2012). Involvement of OsJAZ8 in kasmonate-induced resistance to bacterial blight in rice. Plant Cell Physiol. 53, 2060-2072. doi: 10.1093/pcp/pcs145

Yang, D. L., Li, Q., Deng, Y. W., Lou, Y. G., Wang, M. Y., Zhou, G. X., et al. (2008). Altered disease development in the eui mutants and eui overexpressors indicates that gibberellins negatively regulate rice basal disease resistance. Mol. Plant 1, 528-537. doi: 10.1093/mp/ssn021

Yang, D. L., Yang, Y., and He, Z. (2013). Roles of plant hormones and their interplay in rice immunity. Mol. Plant 6, 675-685. doi: 10.1093/mp/sst056

Yang, D. L., Yao, J., Mei, C. S., Tong, X. H., Zeng, L. J., Li, Q., et al. (2012). Plant hormone jasmonate prioritizes defense over growth by interfering with gibberellin signaling cascade. Proc. Natl. Acad. Sci. U.S.A. 109, E1192-E1200. doi: 10.1073/pnas.1201616109

Yang, Y., Qi, M., and Mei, C. (2004). Endogenous salicylic acid protects rice plants from oxidative damage caused by aging as well as biotic and abiotic stress. Plant J. 40, 909-919. doi: 10.1111/j.1365-313X.2004.02267.x

Yasuda, N., Noguchi, M. T., and Fujita, Y. (2008). Induced rice resistance to blast varies as a function of Magnaporthe grisea avirulence genes. Plant Dis. 92, 1144-1149. doi: 10.1094/Pdis-92-8-1144

Yoshida, H., Yoshino, R., Hashiba, T., and Ehara, Y. (1992). Influence of pyricularia oryzae on leaf growth in rice plants. Tohoku J. Agric. Res. 43, 1-8.

Yoshii, M., Yamazaki, M., Rakwal, R., Kishi-Kaboshi, M., Miyao, A., and Hirochika, H. (2010). The NAC transcription factor RIM1 of rice is a new regulator of jasmonate signaling. Plant J. 61, 804-815. doi: 10.1111/j.1365313X.2009.04107.x

Yoshioka, H., Yoshino, R., Satoh, S., Hashiba, T., and Ehara, Y. (1992). Role of ethylene in stunting of rice infected with rice blast fungus, Pyricularia oryzae Cav. Tohoku J. Agric. Res. 43, 9-14. 
Zhang, Y., and Turner, J. G. (2008). Wound-induced endogenous jasmonates stunt plant growth by inhibiting mitosis. PLOS ONE 3:e3699. doi: 10.1371/journal. pone.0003699

Conflict of Interest Statement: The authors declare that the research was conducted in the absence of any commercial or financial relationships that could be construed as a potential conflict of interest.
Copyright () 2017 Jiang, Liu, Liu, Zhang, Yu and Liang. This is an open-access article distributed under the terms of the Creative Commons Attribution License (CC BY). The use, distribution or reproduction in other forums is permitted, provided the original author(s) or licensor are credited and that the original publication in this journal is cited, in accordance with accepted academic practice. No use, distribution or reproduction is permitted which does not comply with these terms. 